University of South Carolina

Scholar Commons

4-15-2011

\title{
A Bis-Urea Naphthalene Macrocycle Displaying Two Crystal Structures with Parallel Ureas
}

\author{
Michael F. Geer \\ University of South Carolina - Columbia \\ Mark D. Smith \\ University of South Carolina - Columbia, mdsmith3@mailbox.sc.edu \\ Linda S. Shimizu \\ University of South Carolina - Columbia, shimizul@mail.chem.sc.edu
}

Follow this and additional works at: https://scholarcommons.sc.edu/chem_facpub

Part of the Materials Chemistry Commons

\section{Publication Info \\ Published in CrystEngComm, Volume 13, Issue 11, 2011, pages 3665-3669. \\ (C) CrystEngComm 2011, Royal Society of Chemistry.} accepted for inclusion in Faculty Publications by an authorized administrator of Scholar Commons. For more information, please contact digres@mailbox.sc.edu. 


\title{
CrystEngComm
}

\section{A bis-urea naphthalene macrocycle displaying two crystal structures with parallel ureas $\dagger$}

\author{
Michael F. Geer, Mark D. Smith and Linda S. Shimizu* \\ Received 16th February 2011, Accepted 2nd April 2011 \\ DOI: 10.1039/c1ce05207a
}

Herein we synthesized a bis-urea macrocycle from 2,7-dimethylnaphthalene that displays an unusual parallel urea conformation. The naphthalenes also adopt a bowl shape over the anticipated parallel planar orientation. Crystallization of the macrocycle from different solvent systems affords two solvated forms. 1-DMSO. $\left(\mathrm{H}_{2} \mathrm{O}\right)_{2}$ has an extended columnar structure where parallel macrocycles are linked by intervening hydrogen bonded water molecules. In $1 \cdot(\mathrm{MeOH})_{2}$ direct hydrogen-bonds link the macrocycles into chains, which hydrogen-bond with methanol molecules to form a layered structure.

\section{Introduction}

The bulk morphology of materials is important in many aspects of pharmaceuticals because of its impact on a compound's stability and solubility. ${ }^{1}$ In this aspect, it is important for chemists to understand the factors that contribute to or govern the crystal structure and to try to correlate the effect of the structure on properties. ${ }^{2}$ Previously, we have reported on the synthesis and assembly of robust columnar structures formed through self-assembly of bis-urea macrocycles. ${ }^{3}$ The lowest energy conformations of the macrocycle, as predicted by gas phase calculations, together with the preferred anti-parallel arrangement of the ureas and the propensity for aryl-aryl stacking appear to govern their assembly into columnar structures regardless of crystallization conditions. Herein, we report the synthesis of a new bis-urea macrocycle that contains 2,7-dimethylnaphthalene spacer units. This macrocycle displayed two structures that disregard the paradigm typically observed for the assembly of bis-urea macrocycles that usually favors the ureas adopting an anti-parallel alignment. Separate crystallization techniques afford distinct structures that displayed an unusual parallel arrangement of the ureas.

\section{Results and discussion}

Ureas, particularly $N, N^{\prime}$-disubstituted ureas, are reliable supramolecular building blocks that interact with strong 3-centered hydrogen

University of South Carolina, Department of Chemistry and Biochemistry, Columbia, SC, 29208, USA. E-mail: shimizul@chem.sc.edu; Fax: +803777-9521; Tel: $+803-777-2066$

$\dagger$ CCDC reference numbers [813391-813393]. For crystallographic data in CIF or other electronic format see DOI: 10.1039/c1ce05207a bonds to form chains, ${ }^{4}$ sheets, ${ }^{5}$ gels, ${ }^{6}$ and polymers. ${ }^{7}$ Our bis-urea macrocycles consist of two ureas conjoined by " $\mathrm{C}$ "-shaped spacer groups. ${ }^{8}$ The spacer groups were chosen to enforce planar orientations that are beneficial for stacking. Typically, bis-urea macrocycles assembled into columns with the ureas adopting an anti-parallel arrangement of the ureas in a macrocycle presumably to minimize dipole interactions. ${ }^{9}$ A naphthalene spacer unit was investigated to probe the effect of extending the aryl-aryl moiety in the spacer group on the structure and on its subsequent assembly.

The naphthalene bis-urea macrocycle 1 was synthesized in three steps similar to previous reports. ${ }^{8}$ Commercial 2,7-dimethylnaphthalene was brominated under radical conditions to give the required dibromide, which was subsequently cyclized with tert-butyl functionalized triazinanone to yield the protected macrocycle (Fig. 1). The protected macrocycle crystallized through slow evaporation of a 0.1 $\mathrm{mg} \mathrm{mL}^{-1}$ EtOAc : $\mathrm{MeOH}$ solution $(9: 1$ by volume) resulting in a colorless needle crystal suitable for X-ray diffraction. The crystal structure revealed the desired solvent-free macrocycle. The extended structure shows the centrosymmetric macrocycle monomers aligned in a herringbone arrangement (Fig. 2). The naphthalene shelves of the monomer adopt a flat parallel planar arrangement tilted $25^{\circ}$ from the plane of the macrocycle with the ureas oriented anti-parallel (Fig. 2, inset). This is the typically observed conformation for bis-urea macrocycles and was assumed to be beneficial for columnar assembly. ${ }^{3,8-10}$ Since the protected macrocycle 2 crystallized in the expected conformation, we proceeded to deprotect the ureas.

The triazinanone protecting groups were removed by treatment with $20 \%$ acidic diethanol amine solution resulting in free ureas.

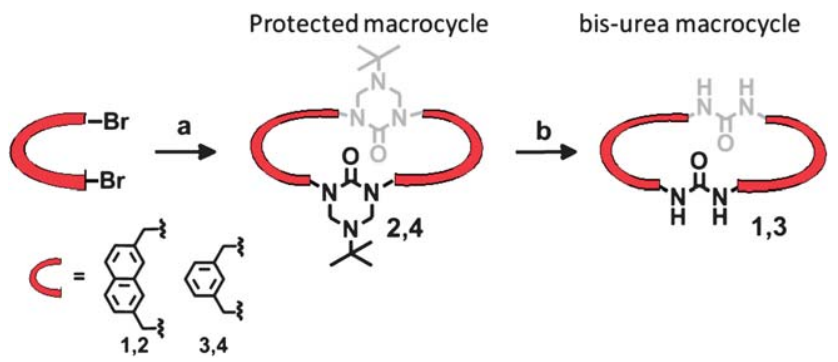

Fig. 1 Schematic synthesis of naphthalene macrocycle. Reagents and conditions: (a) $\mathrm{NaH}$, 5-tert-butyl tetrahydro-1,3,5-triazin-2(1H)-one, THF (2, 15\%), (b) 20\% diethanolammonium chloride aqueous solution in methanol $(\mathbf{1}, 97 \%)$. Typically, bis-urea macrocycles adopt an anti-parallel orientation of the ureas shown above. 


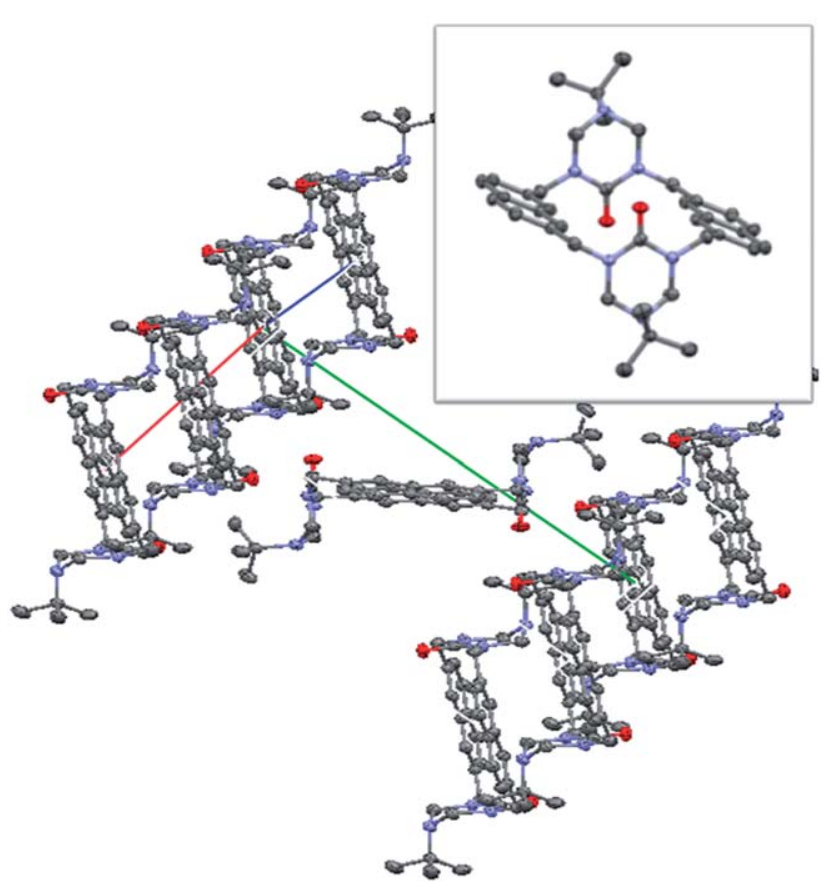

Fig. 2 Crystal packing of the macrocycle displaying the herringbone arrangement of the naphthalene moieties (hydrogens omitted for clarity). (Inset) Crystal structure of single protected macrocycle crystallized from EtOAc/MeOH solution showing the antiparallel urea and parallel planar naphthalene shelves.

The macrocycle was crystallized from a $1 \mathrm{mg} \mathrm{mL}^{-1}$ solution of DMSO and water to form clear colorless rhombic crystals suitable for X-ray analysis (Fig. 3A). The X-ray structure showed the expected macrocycle, but in an unexpected orientation and assembly. The macrocycle 1 crystallized into a columnar structure interpenetrated by two independent water molecules occupying the urea
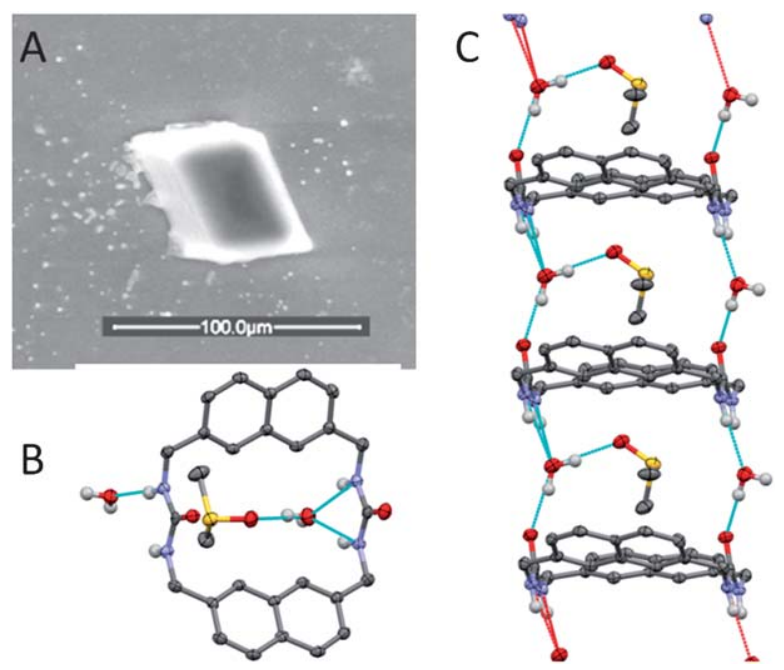

Fig. 3 SEM and crystal structure of macrocycle from DMSO/water solution (some hydrogens have been omitted for clarity). (A) SEM image of the cubic crystal (bar $=100 \mu \mathrm{m}$ ). (B) Single macrocycle showing parallel orientation of the ureas. (C) Single column of macrocycle showing the H-bonding (blue lines) between the water, the ureas and DMSO molecule.
H-bonding sites and by one DMSO molecule (Fig. 3C). The water molecule to the left side of Fig. 3C hydrogen bonds with both nitrogens of the macrocycle above $(\mathrm{N} \cdots \mathrm{O}$ distances $=2.934(3)$ and $3.000(3) \AA)$ and the oxygen below $(\mathrm{O} \cdots \mathrm{O}=2.749(3) \AA)$. This water is also hydrogen bonded to the centrally located DMSO molecule $(\mathrm{O} \cdots$ $\mathrm{O}=2.756(3) \AA)$. The opposite water molecule hydrogen bonds with one nitrogen of the macrocycle above $(\mathrm{N} \cdots \mathrm{O}=3.025(3) \AA)$, to an oxygen of the macrocycle below $(\mathrm{O} \cdots \mathrm{O}=2.777(3) \AA)$, and to a macrocycle carbonyl from a neighboring column $(\mathrm{O} \cdots \mathrm{O}=$ 3.053(3) Å). This expanded columnar structure gives an average distance between macrocycles of $5.3 \AA$ (from urea $\mathrm{N}$ to urea O). This gives an extended columnar structure.

In comparison, most macrocyclic bis-ureas crystallize with an antiparallel arrangement of the urea groups. ${ }^{10}$ It is presumably preferred to minimize the dipole interactions. ${ }^{3,8-10}$ In addition, the ureas typically prefer narcissistic self-assembly with any solvent typically incorporated inside or outside of the columns. ${ }^{3,11}$ For example, the previously reported meta-xylene 3 adopts an anti-parallel arrangement of ureas (Fig. 4A) and assembles into columns via the 3-centered urea-urea self-association (Fig. 4C). ${ }^{8}$ This gives a spacing of $4.614 \AA$ between the urea groups. ${ }^{8}$ In comparison, the parallel aligned ureas of naphthalene 1 (Fig. 4B) forgo the typical urea self-association in favor of an extended structure via intervening water molecules (Fig. 3C). The spacing between ureas in $\mathbf{1}$ is $2.3 \AA$ longer than in the meta-xylene macrocycles. ${ }^{8}$

The observed parallel arrangement of the ureas in naphthalene macrocycle 1 was not observed in its protected precursor 2, which adopted the normal anti-parallel alignment. This suggests the urea groups in $\mathbf{1}$ have some ability to rotate. The naphthalene moieties were arranged in a bowl shape that is oriented toward the electron rich carbonyls instead of the parallel planar orientation that was observed with $m$-xylene macrocycle (Fig. 4). ${ }^{8}$ In addition to the unusual conformation of the macrocycle, the crystal structure suggests ring strain as indicated by a decrease in the bond angle between the methyl connector of the naphthalene and the ureas from the ideal $120^{\circ}$ to $115^{\circ}$ and a $6^{\circ}$ tilting of the ureas from perpendicular to the plane of the macrocycle (Fig. 5).
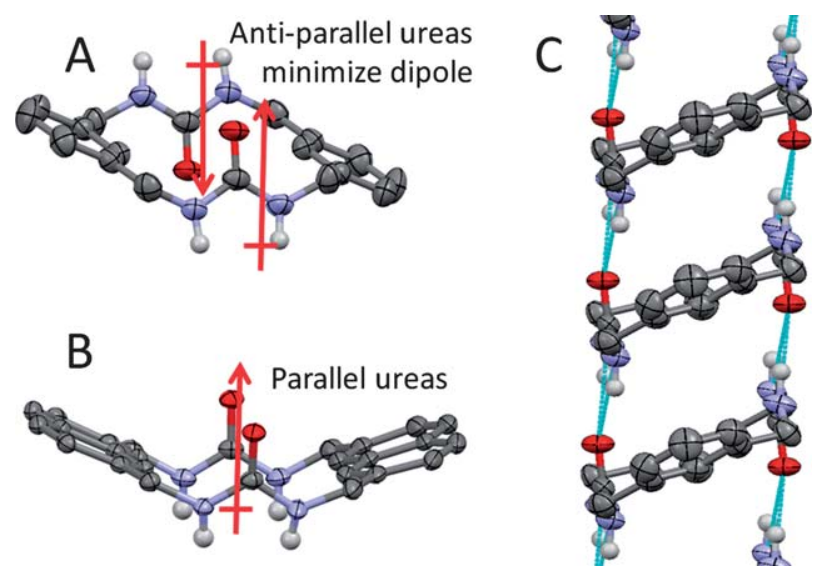

Fig. 4 Comparison of previously reported meta-xylene macrocycle ${ }^{8}$ and naphthalene macrocycle. (A) $m$-Xylenes are in parallel planar arrangement with the ureas in anti-parallel to minimize dipole interaction. ${ }^{8}$ (B) The naphthalenes are in a bowl shape turned toward the carbonyl groups of the ureas that are oriented parallel to each other. (C) The $m$-xylene assembles into columns via 3 -centered urea-urea hydrogen bonds. ${ }^{8}$ 


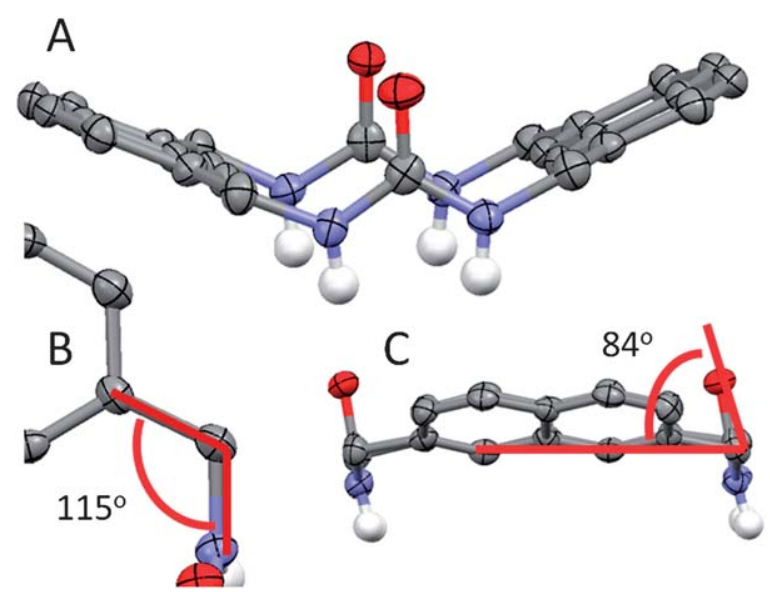

Fig. 5 Naphthalene macrocycle 1. (A) Macrocycle shows a bowl shape orientation of the Naphthalene spacers. (B) Angle between the naphthalene and urea is strained to $115^{\circ}$ from ideal $120^{\circ}$. (C) Side view of macrocycle shows a $6^{\circ}$ tilt of the ureas from perpendicular to the plane of the macrocycle.

Given the unexpected conformation observed, we next set out to observe the assembly of this macrocycle from a series of other solvents including acetonitrile, benzene, DMSO, and methanol. Microcrystals from methanol and benzene were not suitable for $\mathrm{X}$-ray analysis. X-Ray quality hourglass shaped single crystals were obtained by vapor diffusion of a $1 \mathrm{mg} \mathrm{mL}^{-1}$ solution of DMSO by $\mathrm{MeOH}$ (Fig. 6A). The macrocycle crystallized along with two disordered methanol molecules (Fig. 6C). No DMSO molecules were present. The macrocycle retains the bowl-shaped arrangement of the naphthalenes and the parallel oriented ureas, similar to the DMSO/ water crystal (Fig. 6B). The monomers crystallized with an overall lamellar structure consisting of chains of macrocycles directly hydrogen bonded to one another in an offset, tilted fashion (Fig. 6C). The carbonyl of one urea forms hydrogen bonds to the two $\mathrm{NH}$

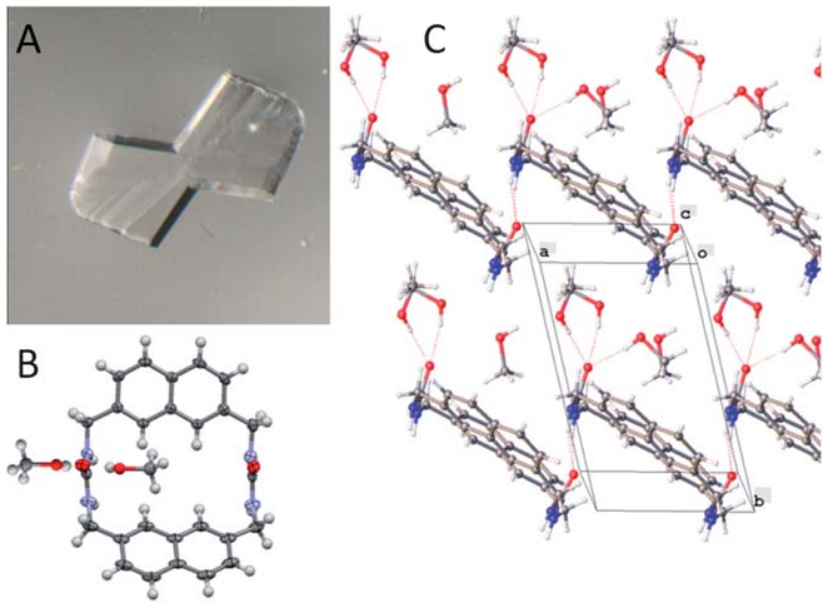

Fig. 6 Image of crystal and single crystal structure of 1 from MeOH/ DMSO solution: (A) optical microscope image of one of the abundant "hourglass" twin crystals at $11.5 \times$ magnification. The dataset was obtained by cleaving such a twin to obtain a single crystal; (B) single macrocycle showing the approximate positions of the disordered $\mathrm{MeOH}$ molecules; (C) crystal packing displaying the lamellar packing of the macrocycles and the $\mathrm{MeOH}$. groups of the neighboring macrocycle urea $(\mathrm{N} \cdots \mathrm{O}=2.826(2) \AA)$. The hydrogen bonded chains of macrocycle were separated by disordered methanol molecules with an average distance between macrocycle of $5.4 \AA$. The $\mathrm{MeOH}$ molecules are hydrogen bonded to the $\mathrm{NH}$ groups and carbonyl oxygens that are not $\mathrm{H}$-bonded to adjacent ureas $(\mathrm{N} \cdots \mathrm{O}=3.053(3)$ and 3.077(4) $\AA$ and $\mathrm{O} \cdots \mathrm{O}$ distances in the range 2.692(3)-2.806(4) $\AA$ ). Once removed from the mother liquor the crystals desolvate beyond X-ray quality.

\section{Experimental}

All chemicals were used as received from commercial sources. NMR were performed on Varian 300 and $400 \mathrm{MHz}$ NMR.

\section{Synthesis of naphthalene bis-urea macrocycle (1)}

Bis(2,7-bromomethyl) naphthalene. $N$-Bromosuccinimide ( $32 \mathrm{mmol}, 5.7 \mathrm{~g}$ ) and 2,7-dimethylnaphthalene $(16 \mathrm{mmol}, 2.5 \mathrm{~g})$ were dissolved in $\mathrm{CCl}_{4}(40 \mathrm{~mL})$. Azobisisobutyronitrile (AIBN) $(5 \%$, $0.80 \mathrm{mmol}, 0.131 \mathrm{~g}$ ) was added, and the reaction mixture was heated to $80^{\circ} \mathrm{C}$ for $18 \mathrm{~h}$. Upon completion, the reaction mixture was cooled to room temperature and the precipitate was filtered off and rinsed with dichloromethane. The filtrate was evaporated in vacuo and the product was purified via column chromatography $(8: 2$ hexanes : dichloromethane) to afford a pale yellow powder $(4.56 \mathrm{~g}$, $90 \%$ ), mp 150-152 ${ }^{\circ} \mathrm{C} .{ }^{1} \mathrm{H}-\mathrm{NMR}\left(300 \mathrm{MHz}, \mathrm{CDCl}_{3}\right): \delta 7.82(\mathrm{~d}, J=$ $8.8 \mathrm{~Hz}, 4 \mathrm{H}), 7.52(\mathrm{~d}, J=8.5 \mathrm{~Hz}, 2 \mathrm{H}), 4.65(\mathrm{~s}, 4 \mathrm{H}) .{ }^{13} \mathrm{C}-\mathrm{NMR}$ $\left(100 \mathrm{MHz}, \mathrm{CDCl}_{3}\right): \delta 135.84,128.60,127.88,127.51,33.73$. Direct probe EIMS (m/z): 314 (calc. for $\mathrm{C}_{12} \mathrm{H}_{10} \mathrm{Br}_{2}: 314.02$ ).

Protected naphthalene macrocycle (2). A 60\% suspension of sodium hydride in mineral oil $(7.5 \mathrm{mmol} \mathrm{NaH}, 0.300 \mathrm{~g})$ and 5-tertbutyl tetrahydro-1,3,5-triazin-2(1H)-one $(2.5 \mathrm{mmol}, 0.39 \mathrm{~g})$ were added to freshly distilled THF and heated at reflux for $1 \mathrm{~h}$. The solution was cooled to room temperature, and a solution of dibromide $(2.5 \mathrm{mmol}, 0.79 \mathrm{~g})$ in $100 \mathrm{~mL}$ THF was added dropwise over 1 $\mathrm{h}$. The reaction mixture was heated to reflux for $48 \mathrm{~h}$ and then cooled to room temperature and neutralized with $20 \mathrm{~mL} 1 \mathrm{~N} \mathrm{HCl}$ and $80 \mathrm{~mL}$ distilled water. The mixture was reduced in vacuo to $\sim 100 \mathrm{~mL}$ and extracted with methylene chloride $(3 \times 100 \mathrm{~mL})$. The organic layer was rinsed with brine and dried over anhydrous magnesium sulfate. The product was isolated by column chromatography $(95: 5$ EtOAc : $\mathrm{MeOH})$ to yield a white crystalline powder $(118.4 \mathrm{mg}, 15 \%)$. ${ }^{1} \mathrm{H}-\mathrm{NMR}\left(400 \mathrm{MHz}, \mathrm{CDCl}_{3}\right): \delta 7.87(\mathrm{~s}, 4 \mathrm{H}), 7.79(\mathrm{~d}, J=8.2 \mathrm{~Hz}, 4 \mathrm{H})$, $7.27(\mathrm{~d}, J=8.6 \mathrm{~Hz}, 4 \mathrm{H}), 5.88(\mathrm{~d}, J=16.2 \mathrm{~Hz}, 4 \mathrm{H}), 4.47(\mathrm{~d}, J=11.5$ $\mathrm{Hz}, 4 \mathrm{H}), 4.22(\mathrm{~d}, J=11.7 \mathrm{~Hz}, 4 \mathrm{H}), 3.84(\mathrm{~d}, J=16.4 \mathrm{~Hz}, 4 \mathrm{H}), 1.20$ (s, 18H). ${ }^{13} \mathrm{C}-\mathrm{NMR}\left(100 \mathrm{MHz}, \mathrm{CDCl}_{3}\right): \delta 155.89,136.05,134.01,131.96$, 127.98, 125.42, 124.42, 63.05, 54.14, 49.37, 28.60. TOF ESI-MS: $m / z$ $619(100 \%)[\mathrm{M}+\mathrm{H}]^{+}$(calc. for $\left.\mathrm{C}_{38} \mathrm{H}_{46} \mathrm{~N}_{6} \mathrm{O}_{2}: 618.81\right)$.

Deprotection of (2) to yield naphthalene macrocycle (1). Protected macrocycle $2(100 \mathrm{mg})$ was added to an aqueous solution of $20 \%$ diethanol amine $(\mathrm{pH} \approx 2)$ and $\mathrm{MeOH}(1: 1$ by volume $)$ and heated at reflux overnight. After cooling, the reaction mixture was neutralized with $10 \mathrm{~mL}$ of $1 \mathrm{~N} \mathrm{HCl}$ and $10 \mathrm{~mL}$ of water. The resulting precipitate was filtered off and rinsed with $1 \mathrm{~N} \mathrm{HCl}(3 \times 10 \mathrm{~mL})$ and water $(3 \times 10 \mathrm{~mL})$ yielding a white crystalline powder $(68 \mathrm{mg}, 97 \%)$. ${ }^{1} \mathrm{H}-\mathrm{NMR}$ (300 MHz, $\delta_{6}$-DMSO): $\delta 7.83(\mathrm{~d}, J=8.5 \mathrm{~Hz}, 4 \mathrm{H}), 7.74$ (s, $4 \mathrm{H}), 7.32(\mathrm{~d}, J=8.2 \mathrm{~Hz}, 4 \mathrm{H}), 6.84(\mathrm{~s}, 4 \mathrm{H}) .{ }^{13} \mathrm{C}-\mathrm{NMR}(100 \mathrm{MHz}$, 
$\delta_{6}$-DMSO): $\delta 158.14,139.74,139.57,133.16,130.90,127.50,124.77$, 42.38 .

\section{Crystallization of naphthalene macrocycle}

Method 1. A dilute solution of 1 in DMSO $\left(1 \mathrm{mg} \mathrm{mL}^{-1}\right)$ was prepared and then diluted again with distilled water (1:1 ratio solution : water by volume). The resulting solution was drop cast onto a glass slide and allowed to evaporate in atmospheric conditions to yield colorless crystals.

Method 2. A solution of 1 in DMSO (1 mg mL $\left.\mathrm{mL}^{-1}\right)$ was prepared and placed into a $3 \mathrm{~mL}$ scintillation vial and the vial was placed into a pint size jar preloaded with $20 \mathrm{~mL}$ methanol. This vapor chamber was allowed to sit in the dark for 2 weeks resulting in colorless crystals. Removal of the crystal from the mother liquor caused them to desolvate.

\section{X-Ray crystallography}

X-Ray intensity data were measured at 150 (2) K or 100(2) K (both forms of 1) using a Bruker SMART APEX diffractometer equipped with Mo $\mathrm{K} \alpha$ radiation $(\lambda=0.71073 \AA$ ). Raw area detector data frame reduction was performed with the SAINT+ program. ${ }^{12}$ Direct methods structure solution, difference Fourier calculations and fullmatrix least-squares refinement against $F^{2}$ were performed with the SHELXTL suite of programs. ${ }^{13}$ All non-disordered non-hydrogen atoms were refined with anisotropic displacement parameters. Hydrogen atoms bonded to carbon were placed in geometrically idealized positions and included as riding atoms. Urea and water hydrogens were located in difference maps and refined isotropically with their $\mathrm{N}-\mathrm{H}$ and $\mathrm{O}-\mathrm{H}$ distances restrained to be approximately equal to those of the same type.

Protected naphthalene macrocycle (2). The compound crystallizes in the space group $P 2_{1} / n$. The asymmetric unit consists of half of one molecule, which is located on a crystallographic inversion center (Table 1).

1. $(\mathbf{M e O H})_{2}$. The compound crystallizes in the triclinic system. The space group $P \overline{1}$ (no. 2) was confirmed by the successful solution and refinement of the structure. The asymmetric unit consists of one cycle and two independent methanol molecules of crystallization. Both methanol molecules are disordered over two roughly equally populated positions, and were refined isotropically with $\mathrm{C}-\mathrm{O}$ distances restrained to $1.45(2) \AA$. Reasonable positions for the four methanolic protons were located in difference maps. Their coordinates were adjusted to $\mathrm{O}-\mathrm{H}=0.85 \AA$ and they were included as riding atoms with $U_{\text {iso, } \mathrm{H}}=1.5 U_{\text {iso, } \mathrm{O}}$. Their positions should be regarded as approximate.

1.DMSO $\cdot\left(\mathbf{H}_{2} \mathrm{O}\right)_{2}$. The compound crystallizes in the space group $P 2_{1} / c$. The asymmetric unit consists of one macrocycle molecule, one DMSO molecule and two water molecules.

\section{Conclusions}

Herein we have synthesized a novel bis-urea macrocycle that utilizes 2,7-dimethylnaphthalene. Crystallization of macrocycle $\mathbf{1}$ resulted in a distinct conformer with unusual parallel urea orientation and bowl shaped monomer. This conformation goes against the expectations set forth by previous studies in bis-urea macrocycles, resulting in an apparent overall dipole of the monomer. This macrocycle also yielded two differently solvated crystal structures from two separate crystallization techniques. The first is an extended columnar structure with water interdigitating the macrocycles. Interestingly, this structure has the parallel ureas all aligned in the same direction giving the single column an overall dipole moment that is balanced by the neighboring columns. The second crystal structure displays lamellar packing of the macrocycle with $\mathrm{MeOH}$. These extended structures bring up an important conformational question. Is the parallel urea

Table 1 Crystal data and refinement data for protected macrocycle (2), and the two crystal structures of bis-urea naphthalene macrocycle (1 - DMSO . $\left(\mathrm{H}_{2} \mathrm{O}\right)_{2}$ and $\left.\mathbf{1} \cdot(\mathrm{MeOH})_{2}\right)$

\begin{tabular}{|c|c|c|c|}
\hline & 2 & $\mathbf{1} \cdot \mathrm{DMSO} \cdot\left(\mathrm{H}_{2} \mathrm{O}\right)_{2}$ & $\mathbf{1} \cdot(\mathrm{MeOH})_{2}$ \\
\hline Empirical formula & $\mathrm{C}_{38} \mathrm{H}_{46} \mathrm{~N}_{6} \mathrm{O}_{2}$ & $\mathrm{C}_{28} \mathrm{H}_{34} \mathrm{~N}_{4} \mathrm{O}_{5} \mathrm{~S}$ & $\mathrm{C}_{28} \mathrm{H}_{32} \mathrm{~N}_{4} \mathrm{O}_{4}$ \\
\hline Formula weight & 618.81 & 538.65 & 488.58 \\
\hline Crystal system & Monoclinic & Monoclinic & Triclinic \\
\hline Space group & $P 2_{1} / n$ & $P 2_{1} / c$ & $P \overline{1}$ \\
\hline$a / \AA$ & $8.8432(11)$ & $7.1366(4)$ & $6.9772(4)$ \\
\hline$b / \AA$ & $18.133(2)$ & $10.9517(6)$ & $10.5977(6)$ \\
\hline$\beta /^{\circ}$ & $111.470(3)$ & $94.278(1)$ & $90.3930(1)$ \\
\hline$\gamma /{ }^{\circ}$ & 90 & 90 & $104.4030(1)$ \\
\hline$V / \AA^{3}$ & $1606.1(3)$ & $2614.9(2)$ & 1227.03(12) \\
\hline$Z$ & 2 & 4 & 2 \\
\hline$D_{\mathrm{c}} / \mathrm{Mg} \mathrm{m}^{-3}$ & 1.280 & 1.368 & 1.322 \\
\hline$\mu / \mathrm{mm}^{-1}$ & 0.081 & 0.171 & 0.090 \\
\hline$F(000)$ & 664 & 1144 & 520 \\
\hline $\mathrm{w} R_{2}$ (all data) & 0.0696 & 0.0748 & 0.1005 \\
\hline$\Delta \rho_{\min , \max } / \mathrm{e} \AA^{-3}$ & $0.139 /-0.143$ & $0.331 /-0.318$ & $0.179 /-0.196$ \\
\hline
\end{tabular}


orientation responsible for the affinity of the ureas with water over the typical urea self-association or are other factors responsible such as ring strain, sterics or the bowl shaped conformation? We are currently investigating larger extended aromatic spacers to probe their properties and see if the parallel urea orientation can be more widely stabilized in crystalline structures. Understanding the interactions that govern the crystal structures will invariably result in better understanding of crystallization and synthetic methods and concurrently a cost saving in the synthetic and pharmaceutical industry.

\section{Acknowledgements}

The authors gratefully acknowledge support for this work from the NSF (CHE-0718171 and CHE-1012298).

\section{References}

1 M. L. Cheney, N. Shan, E. R. Healey, M. Hanna, L. Wojtas, M. J. Zaworotko, V. Sava, S. Song and J. R. Sanchez-Ramos, Cryst. Growth Des., 2010, 10, 394; N. Blagden, M. de Matas, P. T. Gavan and P. York, Adv. Drug Delivery Rev., 2007, 59, 617; J. Bernstein, Polymorphism in Molecular Crystals, Clarendon, Oxford, 2002; H. G. Brittain, Polymorphism in Pharmaceutical Solids, Marcel Dekker, Inc., New York, 1999; R. J. Davey, Chem. Commun., 2003, 1463.

2 G. R. Desiraju, Crystal Engineering: the Design of Organic Solids, Elsevier, New York, 1989.

3 L. S. Shimizu, A. D. Hughes, M. D. Smith, M. J. Davis, P. Zhang, H.-C. zur Loye and K. D. Shimizu, J. Am. Chem. Soc., 2003, 125, 14972; L. S. Shimizu, A. D. Hughes, M. D. Smith and
S. A. Samuel, Supramol. Chem., 2005, 17, 27; M. B. Dewal, Y. Xu, J. Yang, F. Mohammad, M. D. Smith and L. S. Shimizu, Chem. Commun., 2008, 3909.

4 M. C. Etter, Acc. Chem. Res., 1990, 23, 120; Y. L. Chang, M. A. West, F. W. Fowler and J. W. Lauher, 1993, 115, 5991; M. D. Hollingsworth, M. E. Brown, B. D. Satarsiero, J. C. Huffman and C. R. Goss, Chem. Mater., 1994, 6, 1227; C. L. Schauer, E. Matwey and W. Fowler, J. Am. Chem. Soc., 1997, 119, 10245.

5 R. Custelcean, Chem. Commun., 2008, 295; R. Davis, R. Berger and R. Zentel, Adv. Mater., 2007, 19, 3878.

6 J. W. Steed, Chem. Soc. Rev., 2010, 39, 3686.

7 R. K. Castellano, R. Clark, S. L. Craig, C. Nuckolls and J. Rebek, Proc. Natl. Acad. Sci. U. S. A., 2000, 97, 12418-12421; R. P. Sijbesma, R. H. Beijer, L. Brunsveld, B. J. B. Folmer, J. H. K. K. Hirschberg, R. F. Lange, J. K. L. Lowe and E. W. Meijer, Science, 1997, 278, 1601.

8 L. S. Shimizu, M. D. Smith, A. D. Hughes and K. D. Shimizu, Chem. Commun., 2001, 1592.

9 D. Ranganathan, V. Haridas, C. Sundari, D. Balasubramanian, K. P. Madhusudanan, R. Roy and I. L. Karle, J. Org. Chem., 1999, 64, 9230; J. H. Leohlin, M. C. Etter, C. Gendreau and E. Cervasio, Chem. Mater., 1994, 6, 1206; K.-S. Huang, D. Britton, M. C. Etter and R. Byrn, J. Mater. Chem., 1995, 5, 379.

10 J. Yang, M. B. Dewal, D. Sobransingh, M. D. Smith, Y. Xu and L. S. Shimizu, J. Org. Chem., 2009, 74, 102; L. Fischer, M. Decossas, J.-P. Briand, C. Didierjean and G. Guichard, Angew. Chem., Int. Ed., 2009, 48, 1625; D. Meshcheryakov, V. Boehmer, M. Bolte, V. Hubscher-Bruder and F. Arnaud-Neu, Chem.-Eur. J., 2009, 15, 4811; F. Boehme, C. Kunert, H. Komber, D. Voigt, P. Friedel, M. Khodja and H. Wilde, Macromolecules, 2002, 35, 4233.

11 K. Roy, C. Wang, M. D. Smith, M. B. Dewal, A. C. Wibowo, J. C. Brown, S. Ma and L. S. Shimizu, Chem. Commun., 2011, 47, 277.

12 SMART Version 5.630, SAINT+ Version 6.45, Bruker Analytical XRay Systems, Inc., Madison, Wisconsin, USA, 2003.

13 G. M. Sheldrick, Acta Crystallogr., Sect. A: Found. Crystallogr., 2007, 64, 112. 